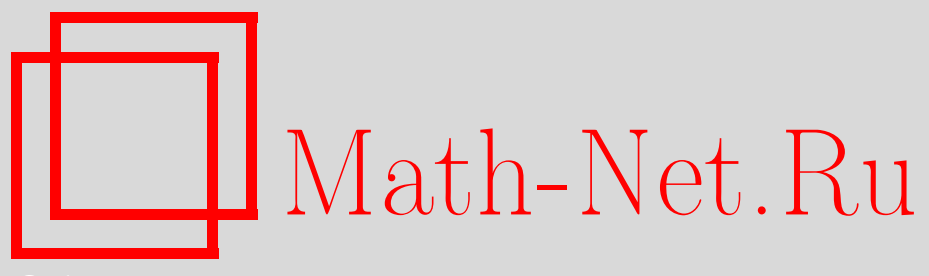

В. И. Бердышев, В. А. Каминский, С. В. Конягин, Б. П. Осиленкер, М. В. Самохин, С. А. Теляковский, И. Г. Царьков, В. А. Шматков, Александр Львович Гаркави (некролог), УМH, 2008, том 63, выпуск 3, 147-148

DOI: https://doi.org/10.4213/rm9201

Использование Общероссийского математического портала Math-Net.Ru подразумевает, что вы прочитали и согласны с пользовательским соглашением http://www.mathnet.ru/rus/agreement

Параметры загрузки:

IP : 3.93 .64 .190

26 апреля 2023 г., 14:39:21

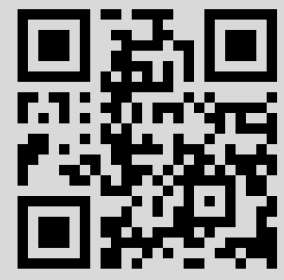




\section{Александр Львович Гаркави}

7 сентября 2007 года на 83-м году жизни скончался известный математик, доктор физико-математических наук, профессор Александр Львович Гаркави. Он родился 10 ноября 1924 г. в Ростове-на-Дону. Его отец был крупный инженер-энергетик, мать - бухгалтер. В 1942 г., после окончания школы, А. Л. Гаркави был призван в Красную Армию. После окончания войны он остается в рядах защитников Родины и демобилизуется в конце 1950 г., имея многие боевые награды.

Незаурядных способности А. Л. Гаркави позволили ему после девятилетнего перерыва с момента окончания школы поступить на механико-математический факультет Львовского университета и с отличием окончить его в 1956 г. В том же году он был принят в аспирантуру Математического института им. В. А. Стеклова АН СССР, где его научным руководителем был

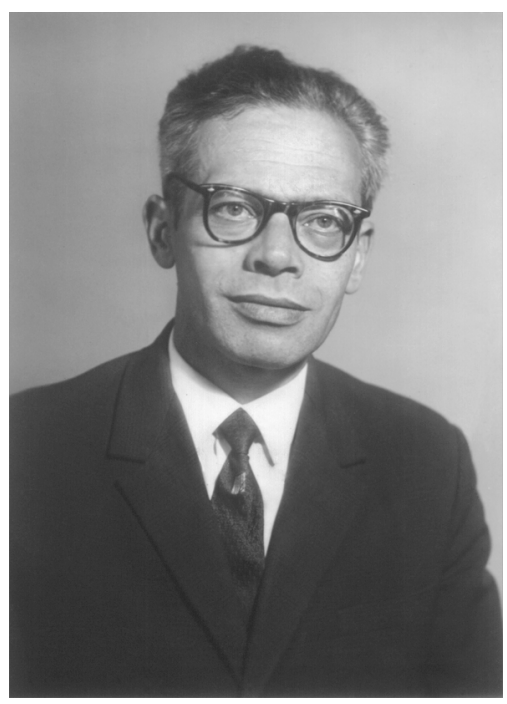
профессор С. Б. Стечкин. В 1959 г. А. Л. Гаркави защищает кандидатскую диссертацию, в 1966 г. - докторскую.

Большинство работ А. Л. Гаркави относится к теории приближений и геометрии банаховых пространств. Им получены интересные результаты о совместном приближении периодических функций и их производных тригонометрическими полиномами.

В 1961 г. А.Л. Гаркави опубликовал соотношения двойственности в задаче наилучшего приближения элементами произвольного выпуклого множества в банаховом пространстве. Эти результаты существенно дополнили хорошо известные к тому времени соотношения двойственности С. М. Никольского и М.Г. Крейна, относящиеся к аппроксимации линейными подпространствами. Соотношения двойственности дают возможность удобного и единообразного подхода к вопросам чебышёвского круга идей в теории аппроксимации: критерии элемента наилучшего приближения, единственность или множественность таких элементов, вычисление или оценки величины наилучшего приближения, алгоритмы построения наилучшего приближения.

Значительную роль в теории аппроксимации играют теоремы об "очистке". В случае аппроксимации в пространстве непрерывных функций, заданных на некотором множестве $S$, такие теоремы показывают, что аппроксимацию на $S$ можно заменить аппроксимацией на "расчищенном" множестве, чаще всего - конечном. Первая теорема такого рода, полученная Валле Пуссеном, относилась к полиномиальной аппроксимации на отрезке. В общем случае аппроксимации в банаховом пространстве в качестве множества $S$ выступает единичный шар сопряженного пространства (элементы пространства можно трактовать как непрерывные функции на $S$, снабженном слабой* 
топологией). А. Л. Гаркави принадлежат весьма общие теоремы об очистке, заменяющие аппроксимацию на $S$ аппроксимацией на определенных подмножествах $S$, содержащих только крайние точки $S$. В этих и многих других вопросах весьма полезна высказанная в неполной форме И. Зингером, а в полной форме доказанная А. Л. Гаркави (и независимо Г. Шоке) лемма о продолжении функционалов, являющихся крайними точками единичного шара. А. Л. Гаркави доказал также ряд теорем об очистке в экстремальных задачах, более общих, чем задача наилучшего приближения.

Глубокие результаты получены А.Л. Гаркави в исследовании аппроксимативных свойств подпространств конечной коразмерности и решении соответствующих двойственных экстремальных задач теории моментов. Ему принадлежит пример бесконечномерного банахова пространства, не содержащего нетривиальных чебышёвских подпространств.

В ряде работ А. Л. Гаркави исследовал вопросы существования наилучшей $N$-сети, наилучшего $N$-покрытия и, в частности, чебышёвского центра как для множеств в произвольных банаховых пространствах, так и в метриках $C$ и $L$. Понятие наилучшей $N$-сети и родственное понятие наилучшего $N$-покрытия порождены исследо-

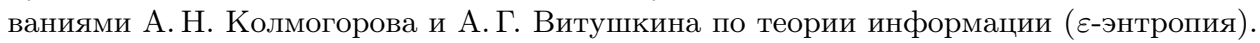
Тонкость этих проблем иллюстрируется следующим установленным А.Л. Гаркави фактом: в каждом банаховом пространстве для любого множества из $N+1$ точки существует наилучшая $N$-сеть, но существует банахово пространство, в котором некоторые множества из $N+2$ точек не обладают наилучшей $N$-сетью.

Некоторые введенные Александром Львовичем понятия (чебышёвский центр, почти чебышёвское множество, равномерная выпуклость по направлениям и др.) стали общепринятыми и получили развитие у многих исследователей.

Ряд выполненных А. Л. Гаркави работ посвящен наилучшим приближениям в пространствах векторнозначных функций. Это направление начало развиваться после работ С. И. Зуховицкого и С. Б. Стечкина в середине пятидесятых годов. А. Л. Гаркави исследовал вопрос о влиянии свойств пространства значений на чебышёвский ранг системы векторнозначных функций, в частности, на условие Хаара.

А. Л. Гаркави получены теоремы существования для весьма общих интегральных функционалов и теоремы существования наилучших приближений в некоторых пространствах Фреше измеримых функций. В дальнейшем в сферу его научных интересов попали принципиальные вопросы существования наилучших приближений подпространствами суперпозиций функций меньшего числа переменных.

А. Л. Гаркави интересовали приложения математики в инженерных задачах. Им опубликован ряд работ, связанных с использованием теории надежности. В 1982 г. одна из этих работ была удостоена премии Госстроя СССР. Всего А. Л. Гаркави опубликовал более 100 научных и научно-методических работ.

Он преподавал математику в различных высших учебных заведениях, с 1977 г. был профессором кафедры высшей математики Московского государственного строительного университета. И его лекции в студенческих аудиториях, и доклады на семинарах, международных конференциях и симпозиумах отличались скрупулезной добросовестностью, методической продуманностью, четкостью и лаконичностью.

Обладая богатым научным потенциалом и трудолюбием, он много времени уделял не только своим ученикам, которые, защитив диссертации, работают в вузах России и за рубежом, - многие его коллеги при выполнении своих работ и диссертаций были благодарны ему за внимание, советы и консультации.

Всегда спокойный, доброжелательный, глубоко порядочный и необычайно скромный - именно таким он останется в памяти всех близко знавших его коллег, товарищей, друзей. 